\title{
In vivo multiphoton imaging of immune cell dynamics
}

\author{
Takaharu Okada ${ }^{1,2,3} \cdot$ Sonoko Takahashi ${ }^{1,2}$. \\ Azusa Ishida $^{1,2} \cdot$ Harumichi Ishigame ${ }^{1}$
}

Received: 14 August 2016/Revised: 7 September 2016/Accepted: 12 September 2016/Published online: 22 September 2016

(C) The Author(s) 2016. This article is published with open access at Springerlink.com

\begin{abstract}
Multiphoton imaging has been utilized to analyze in vivo immune cell dynamics over the last 15 years. Particularly, it has deepened the understanding of how immune responses are organized by immune cell migration and interactions. In this review, we first describe the following technical advances in recent imaging studies that contributed to the new findings on the regulation of immune responses and inflammation. Improved multicolor imaging of immune cell behavior has revealed that their interactions are spatiotemporally coordinated to achieve efficient and long-term immunity. The use of photoactivatable and photoconvertible fluorescent proteins has increased duration and volume of cell tracking, even enabling the analysis of inter-organ migration of immune cells. In addition, visualization of immune cell activation using biosensors for intracellular calcium concentration and signaling molecule activities has started to give further mechanistic insights. Then, we also introduce recent imaging analyses of interactions between immune cells and non-immune cells including endothelial, fibroblastic, epitheli$\mathrm{al}$, and nerve cells. It is argued that future imaging studies that
\end{abstract}

Electronic supplementary material The online version of this article (doi:10.1007/s00424-016-1882-x) contains supplementary material, which is available to authorized users.

Takaharu Okada

takaharu.okada@ riken.jp

1 Laboratory for Tissue Dynamics, RIKEN Center for Integrative Medical Sciences, Yokohama, Kanagawa 230-0045, Japan

2 Graduate School of Medical Life Science, Yokohama City University, Yokohama, Kanagawa 230-0045, Japan

3 PRESTO, Japan Science and Technology Agency, Kawaguchi, Saitama 332-0012, Japan apply updated technical advances to analyze interactions between immune cells and non-immune cells will be important for thorough physiological understanding of the immune system.

Keywords Multiphoton microscopy · Immune response · Intravital imaging $\cdot$ Photoconversion

\section{Introduction}

The immune system is comprised of diverse immune cell types. Different types of immune responses against various pathogens and environmental antigens need to employ different combinations of immune cells that interactively work together. Therefore, it is important to understand which types of immune cells are interacted with each other in specific locations in tissues at specific timings during each type of immune responses. Live imaging analysis with the $3 \mathrm{D}$ resolution at the cellular level using multiphoton laser excitation fluorescent microscopy (hereafter called multiphoton microscopy) provides vital information to understand in vivo cellular interactions. Earlier than in the immunology field, multiphoton microscopy was applied for live tissue imaging in the field of neuroscience in 1990s [10]. Real-time imaging of immune cell behavior in excised, re-aggregated, or in vivo tissues using multiphoton or single-photon laser microscopy was first reported in 2002 to 2003 [7, 45, 46, 67]. Since then, many techniques have been developed and applied to visualize various immunological events by multiphoton microscopy [16, 31].

Recently, for deeper understanding of complex but organized communications between immune cells, it is increasingly necessary to simultaneously track behavior of multiple 
immune cell types with high multicolor imaging performance. Another issue of multiphoton imaging is time and space limitations for tracking of highly motile immune cells, and photoactivatable and photoconvertible fluorescent proteins have been successfully utilized to extend these limits. Moreover, in order to obtain functional insights from imaging analysis, various reporters of cellular and molecular activities have been also employed for immune cell imaging. These reporters include not only genetically encoded calcium and apoptosis indicators, which have been used in neuroscience and developmental biology, but also a reporter of the MAP kinase activity, which was developed by cancer cell biologists. In this review, we introduce recent studies on immune cell dynamics and interactions utilizing the improved imaging techniques. Because there are recent excellent reviews on in vivo multiphoton imaging and imaging of immune cells, we mainly focus on the new studies and technical aspects that were not extensively described by the previous reviews $[31,60]$. Then, we highlight recent studies that visualized interactions of immune cells with non-immune cells, and discuss future directions to study the regulation of immune responses and inflammation by the various systems of the body.

\section{Multicolor imaging of various immune cell types}

In order to visually understand how cell migration and interactions underlie immune responses in vivo, it is helpful and often necessary to simultaneously get the picture of the tissue microenvironment where observation target events take place. For example, high affinity antibodies, which are an important arm of the immune system, are produced in a specialized structure, the germinal center formed in the lymphoid tissues during the immune response. Within the germinal center, antigen-specific B cells proliferate and mutate their antibody genes. B cells that have improved the affinity of their antibodies to antigens presented in the germinal center are positively selected by helper $\mathrm{T}$ cells to further proliferate and differentiate to antibody-secreting cells $[1,76]$. For identifying germinal centers by in vivo imaging, it is useful to visualize the segregation of proliferating $\mathrm{B}$ cells and quiescent naïve $\mathrm{B}$ cells, which are not directly involved in ongoing immune responses [20, 35, 50]. Visualization of follicular dendritic cells, which present antigens in the form of immune complexes in germinal centers, can be also used to visually locate germinal centers $[2,77]$. Thus, imaging with three colors or more is usually conducted to analyze migration and interactions of $\mathrm{B}$ cells and helper T cells in germinal centers.

Another example of the contribution of multicolor imaging can be found in recent research on the mechanism of longterm immunity by cytotoxic $\mathrm{T}$ cells, which are particularly important for viral and tumor immune responses. In this type of immune responses, again, helper $\mathrm{T}$ cells play an important role. As described above, some helper T cells migrate into germinal centers to control B cell responses, but others remain in the $\mathrm{T}$ cell zone of lymph nodes to help cytotoxic $\mathrm{T}$ cell activation and differentiation to long-lived memory $\mathrm{T}$ cells [6]. In most immune responses, $\mathrm{T}$ cell activation, expansion, and differentiation require interactions with antigenpresenting cells called dendritic cells. Within lymph nodes, there are various subsets of dendritic cells in different microenvironments [17, 25]. Generally, helper T cells are developed from naïve $\mathrm{CD}^{+} \mathrm{T}$ cells, and cytotoxic $\mathrm{T}$ cells from naïve $\mathrm{CD} 8^{+} \mathrm{T}$ cells after these naïve $\mathrm{T}$ cells are activated by dendritic cells. Several recent imaging studies showed that in the early phase of immune responses, naïve $\mathrm{CD}^{+} \mathrm{T}$ cells and naïve $\mathrm{CD}^{+} \mathrm{T}$ cells are activated by interactions with different subsets of dendritic cells in different locations [12, 18, 29, 36]. Interestingly, by comparing the results of these studies, it is suggested that subsets of dendritic cells involved in the early activation of $\mathrm{CD}^{+} \mathrm{T}$ cells and $\mathrm{CD} 8^{+} \mathrm{T}$ cells vary depending on the form of antigens and types of pathogens. In contrast, two of these studies using different viral infection models showed that after helper $\mathrm{T}$ cells and cytotoxic $\mathrm{T}$ cells are developed, both of them start interacting with a single subset of dendritic cells, which can be identified by the hallmark expression of a chemokine receptor XCR 1 and presents antigens for both cytotoxic $\mathrm{T}$ cells and helper $\mathrm{T}$ cells $[12,29]$. Through the "two-on-one" antigen-specific interactions, helper T cells potentiate function of the dendritic cell subset by providing cytokine and other signals, and cytotoxic T cells are maximally activated and become long-lived through the interaction with the potentiated XCR $1^{+}$dendritic cells [6].

Differentiated helper $T$ cells and cytotoxic $T$ cells leave the lymph node to enter other tissues in which antigens and pathogens infiltrated. Then, they promote immune responses and inflammation in the tissues by interacting with local dendritic cells. An imaging study described that in the antigen-induced contact dermatitis model, dermal macrophages draw in dermal dendritic cells to form distinct clusters. Skin-infiltrated antigen-specific T cells swarm around and interact with the clustered dendritic cells, forming intense inflammation sites, which are suggested to be a cause of the eczematous vesicle formation [52]. Improved multicolor imaging shows that the dendritic cell clusters contain both XCR $1^{+}$and $\mathrm{XCR} 1^{-}$dendritic cells, and that both helper $\mathrm{T}$ cells and cytotoxic $\mathrm{T}$ cells swarm around the clusters (Fig. 1a, c; and Movie S1). Interestingly, the apex of some of the dendritic cell clusters seems to stick up into the epidermis, and helper $\mathrm{T}$ cells and cytotoxic $\mathrm{T}$ cells swarming in the dermis are observed to enter the epidermis at the apex of the dendritic cell clusters (Fig. 1b, d; and Movie S2). Some of these $\mathrm{T}$ cells, especially cytotoxic T cells, may stay in the epidermis to become tissue-resident memory $\mathrm{T}$ cells in preparation for future invasions [26]. 


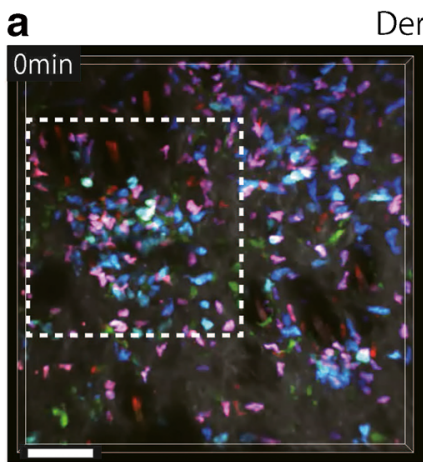

Dermis

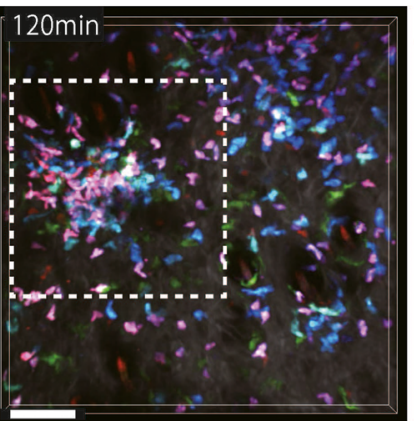

b

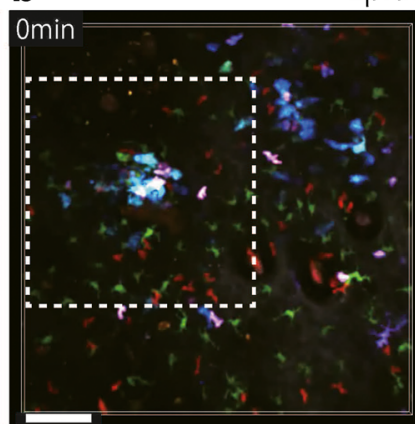

Epidermis

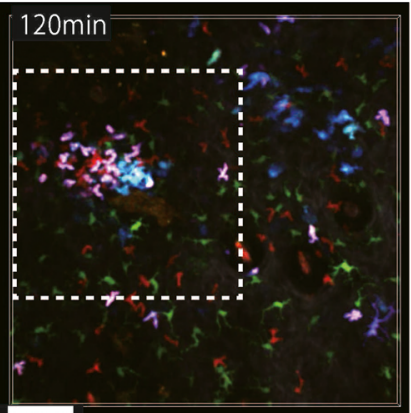

c
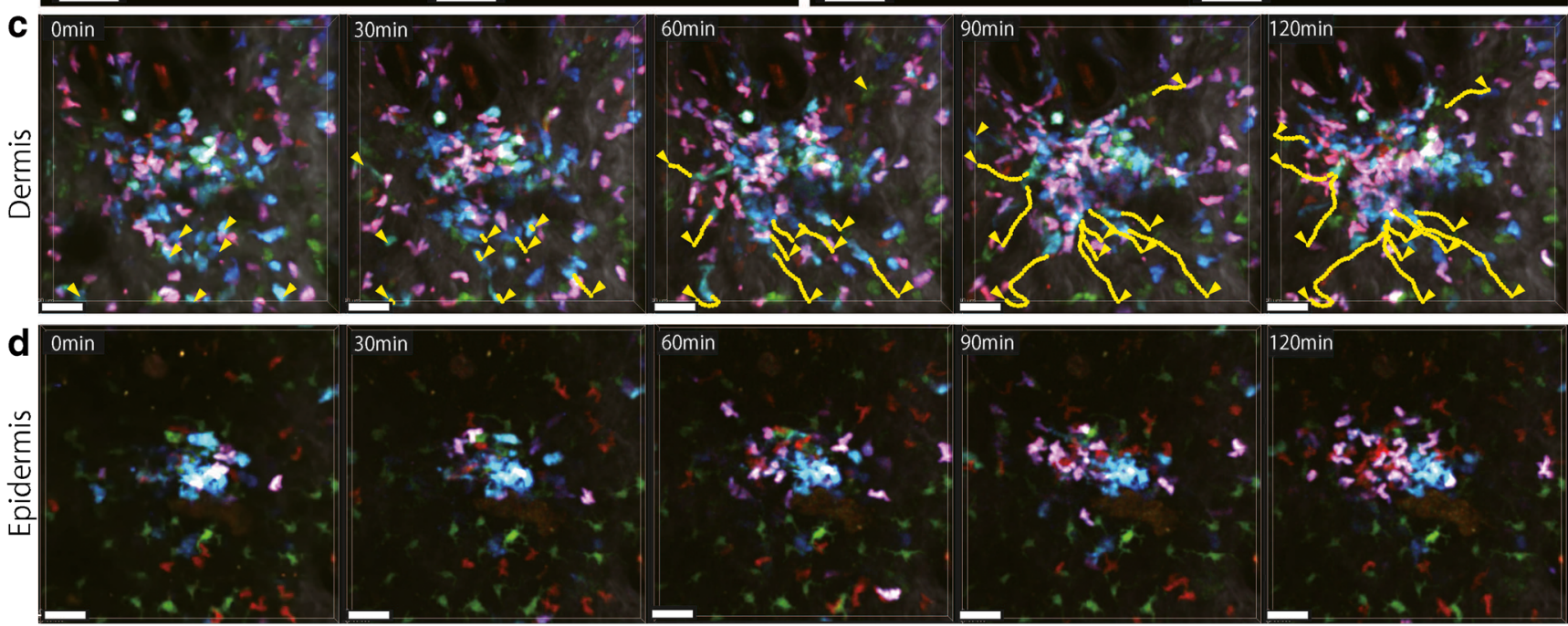

$60 \mathrm{~min}$
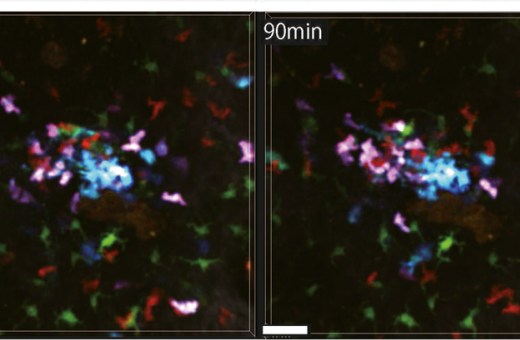

inverted multiphoton microscope with four external detectors. Excitation wavelength was $910 \mathrm{~nm}$. a Projection images of ten $z$-slices of the dermis (33-60- $\mu \mathrm{m}$ depth from the skin surface) at the beginning and end of the 2-h recording. Scale bar: $80 \mu \mathrm{m}$. Collagen fibers (white) were also visualized by second harmonic generation. b Projection images of four $z$-slices of the epidermis (12-21- $\mu \mathrm{m}$ depth from the skin surface) at the same $x-y$ position as a. The scattered epidermal dendritic cells in green are mostly Langerhans cells. c, $\mathbf{d}$ Time-lapse images of the region indicated by dotted lines in a and b. Scale bar: $40 \mu \mathrm{m}$. Yellow lines in $\mathbf{c}$ are paths of dendritic cell migration tracked every minute. Yellow arrowheads indicate starting positions of the tracks

In addition to the diversity of immune cells involved in immune responses in terms of their lineages and differentiation states, extreme diversity exists in the clonality of antigen receptor gene rearrangement in $\mathrm{B}$ and $\mathrm{T}$ cells. To visually estimate the clonality of B cells involved in each of germinal centers, a recent study utilized a multicolor imaging method based on "Brainbow," which was originally developed for analysis of neural circuits and was also applied for fatemapping analysis of epithelial stem cells and cells in the immune system such as Langerhans cells and follicular dendritic cells $[19,32,65,70]$. By combining the imaging method with sequencing of the immunoglobulin genes of individual B cells from each germinal center, the study showed that B cell competition to achieve affinity maturation progressed in various manners in individual germinal centers in the same lymph node [70].

\section{Longitudinal tracking of immune cells}

Immune responses usually take days or longer from the onset to come to the peak, and weeks or longer to wane. In order to interpret the results of immune cell migration and interactions and understand their roles in immune responses, it is often important to identify and analyze imaged cells a day or more after their behavior of interest is observed, either by continuously tracking them or by labeling them during imaging. Although continuous intravital imaging over a day is feasible to see changes occurring in the particular part of tissues [52], it is usually difficult to continuously track individual motile cells within limited imaging volumes for more than an hour. Therefore, labeling cells of interest during imaging for later analysis is an attractive approach. Photoactivatable fluorescent proteins such as PA-GFP [54] or photoconvertible ones 
like Kaede [3] and KikGR [74] enable light-induced labeling of target cells during imaging. Usually, photoactivation and photoconversion of these photochromic fluorescent proteins are performed by irradiation with intense violet light. However, this single-photon irradiation method lacks spatial resolution in the direction of travel of irradiation light (usually the tissue-depth direction). In contrast, multiphoton irradiation at $\sim 720-840 \mathrm{~nm}$ allows photoactivation or photoconversion of PA-GFP, Kaede, or KikGR in a microscopically defined 3D volume to specifically label cells of interest $[8,61,77]$. By optimizing the multiphoton irradiation method, the destination of $\mathrm{B}$ cells and helper T cells, which had been observed in specific anatomical locations in the lymph node at the time of irradiation, was analyzed several hours to a day later $[62,68,77]$.

In most of the previous studies, mice expressing PA-GFP, Kaede, or KikGR ubiquitously in the whole body were used for flow cytometric analysis after irradiation or as donors of transplantable immune cell types [62, 68, 72, 73, 77]. However, mice that express the photochromic proteins in specific subsets of immune cells have been also generated [36]. The abovementioned XCR $1^{+}$dendritic cells in the lymph node are actually a mixture of a population that develops in the lymph node and a population that develops in other organs including the skin and then migrates to the lymph node. By irradiating the skin of a knock-in mouse strain harboring the KikGR gene inserted in the Xcrl locus, these two populations of XCR $1^{+}$ dendritic cells in the lymph node can be distinguished by in vivo imaging to analyze their interactions with T cells [36].

When photoactivation or photoconversion is induced in cells within microscopically defined volumes by multiphoton irradiation, it is important to carefully determine the optimal laser intensity and exposure time for each experiment. A continuous exposure with high-power laser would damage cells and tissues, whereas a brief exposure with moderate-power laser would only photoactivate or photoconvert a small number of the fluorescent proteins. In the studies that used Kaede mice, two-photon irradiation with a moderate-power laser was repeated several thousand times to complete photoconversion of cells in the lymph node $[8,68]$. KikGR-expressing dendritic cells in the lymph node can be photoconverted by using a similar irradiation protocol (Fig. 2). Specific photoconversion of motile target cells may require cell tracking during repeated irradiation or transient reduction of motility by lowering tissue temperature during repeated irradiation.

\section{Fluorescent indicators to visualize immune cell activities}

For understanding the roles for immune cell migration and interactions, simultaneous visualization of cellular states and function by using molecular probes provides important information. The probes are either small molecule fluorescent indicators or fluorescent protein-based biosensors. Small molecule fluorescent indicators have been used to detect events such as changes in intracellular calcium concentrations $[57,79]$ and the generation of reactive oxygen species [11] in immune cells. Selective visualization of molecular events associated with endogenous target cells with small molecule fluorophores often requires ingenious in vivo labeling methods. For example, a recent study developed a $\mathrm{pH}$-activatable small molecule probe that is fixed on the bone surface after the in vivo administration and reported intravital imaging of the bone resorption activity of osteoclasts [42].

Fluorescent protein-based biosensors have the advantages that they can be expressed selectively in target cells and are not diluted in proliferating cells. Intracellular calcium increases $[39,40,51,63,71,83]$, nuclear translocation of the transcription factor, nuclear factor of activated T cells (NFAT) [41, 43, 56], and caspase 3 activation during apoptosis [15] were visualized in T cells or B cells in vivo by using biosensors. There are two types of biosensors available to monitor intracellular calcium increases. One is to detect Förster resonance energy transfer (FRET) as changes in either the acceptor-to-donor fluorescence intensity ratio or the donor fluorescence lifetime [39, 40, 51, 64, 71, 80, 82, 83]. The other is to simply detect changes in the fluorescence intensity of biosensors $[14,63,80]$. Both types of calcium biosensors have been recently used to visualize calcium increases in helper $T$ cells interacting with $\mathrm{B}$ cells in germinal centers. These studies have suggested that productive interactions with B cells induce calcium increases in helper $\mathrm{T}$ cells to enhance signaling for positive selection of the B cells [40, 63].

FRET biosensors have been also developed to monitor the activities of small GTPases and various kinases that are important for intracellular signaling in diverse types of cells $[4,37,82]$. Among them, transgenic mouse lines ubiquitously expressing biosensors for ERK and PKA were recently established and utilized for in vivo multiphoton imaging [27, 33]. As for immune cell imaging, the ERK activity was monitored in granulocytes during their extravasation or accumulation to damaged tissue sites [33, 48, 49].

\section{Imaging of interactions between immune cells and non-immune cells}

Development, differentiation, and function of immune cells are dependent on and regulated by tissue microenvironment composed of non-immune cells. For instance, immigration of immune cells from the blood flow to the parenchyma of specific organs requires their interactions with diverse types of endothelial cells. For intravital imaging of 


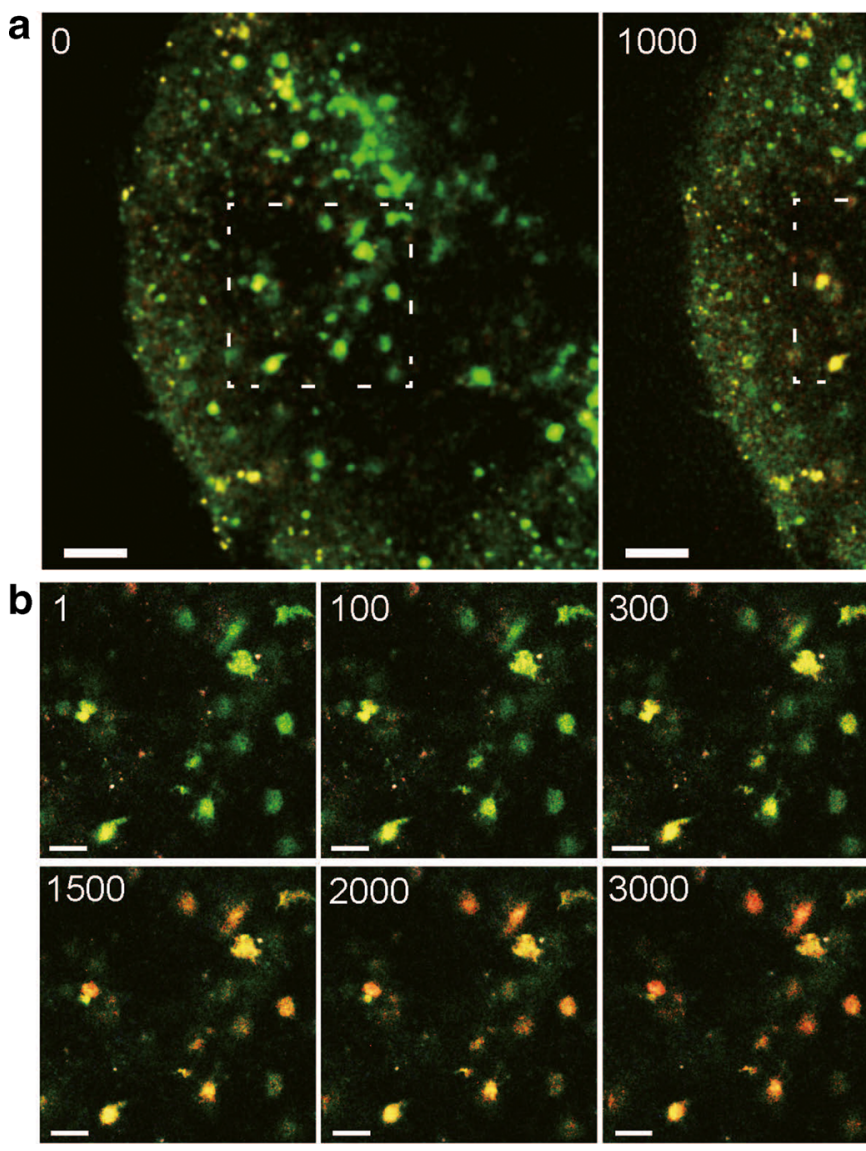

Fig. 2 Multiphoton photoconversion of KikGR-expressing cells in the ex vivo lymph node. An inguinal lymph node was excised from an $X c r 1^{K i k G R /+}$ mouse [36], and imaged and irradiated by multiphoton microscopy. a Single $x y$-slice images of the lymph node. Excitation wave length was $800 \mathrm{~nm}$. The numbers indicate the number of times of

non-immune cells in lymph nodes, transgenic mice ubiquitously expressing GFP were lethally irradiated and transplanted with bone marrow cells from non-fluorescent mice [5] or mice with the CFP transgene [47]. Using such bone marrow chimeric mice, lymphocyte migration through the endothelium of high endothelial venules to the lymph node parenchyma was imaged with multiphoton microscopy $[5,47]$. The study also visualized the network of fibroblastic reticular cells as the tissue framework for lymphocyte migration in the lymph node parenchyma [5]. Lymphocyte emigration from the lymph node parenchyma into the lymphatic sinuses was also studied by multiphoton microscopy. In these studies, the lymphatic endothelium was visualized by administration of a fluorescent dyelabeled antibody against Lyve-1, the surface marker of lymphatic endothelial cells $[22,23]$, or a fluorescent dyelabeled lectin [78]. In addition, several lymphatic reporter mouse strains have been developed [28]. In the skin, the interaction between myeloid cells and pericytes around arterioles and capillaries in the inflammatory conditions was analyzed by intravital microscopy [66].

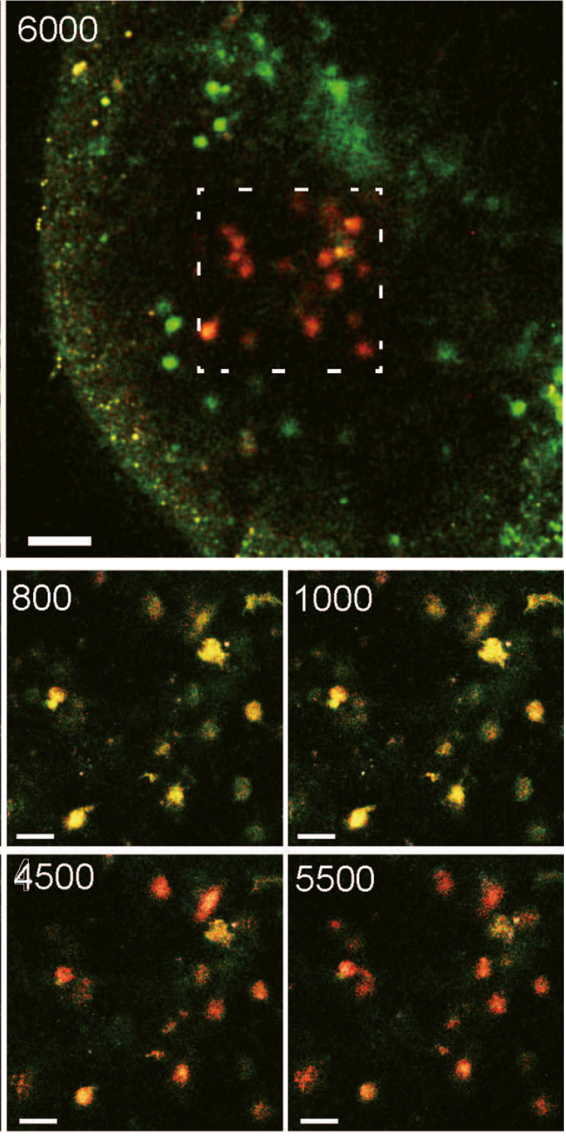

840-nm irradiation in the dotted line region before each image was recorded. Scale bar: $50 \mu \mathrm{m}$. b Single $x y$-slice images of the dotted line region in a. The images were recorded during 840-nm irradiation. The image size was $512 \times 512$ pixels, and laser dwell time during each $x y$ scan was about $1.6 \mu \mathrm{s} /$ pixel. Scale bar: $20 \mu \mathrm{m}$

In the barrier tissues such as the intestine and skin, immune cell interactions with epithelial cells are pivotal for antigen transport and pathogen recognition. An imaging study showed that goblet cells, an epithelial cell type that secretes mucus into the gut lumen, take in soluble antigens from the lumen and pass them to a subset of dendritic cells in the lamina propria of the small intestinal villi [44]. Another study visualized that lamina propria dendritic cells vigorously stick out and retract their processes between epithelial cells to capture pathogens from the lumen [13]. More recently, dynamics of two suppressive $T$ cell types in the intestine, which are believed to be important for the regulation of immune responses and inflammation, were visualized. One subset is regulatory T cells that are found mainly in the lamina propria, and the other is called intraepithelial lymphocytes (IELs). It was suggested from the imaging and other experiments that regulatory $\mathrm{T}$ cells that moved from the lamina propria to the epithelium were converted to IELs in a microbiota-dependent fashion. These T cells might occasionally migrate between epithelial cells to briefly poke out to the luminal side [69]. Although it is unclear how dendritic cell processes and T cells could make it through 
the tight junctions between epithelial cells, these events might be associated with dynamics of epithelial cells and tight junctions [24]. In the skin epidermis, when Langerhans cells, a subset of dendritic cells located in the epidermis, stick out their processes through the tight junctions between keratinocytes to sample external antigens, local remodeling of the tight junctions takes place to allow the penetration by processes of Langerhans cells [38]. The dynamics of this remodeling process, however, has not been analyzed by intravital microscopy.

Regulation of the immune system and inflammation by the peripheral nervous system has been studied for a long time, and is beginning to recapture a great amount of attention $[53,75]$. In pharmacologically induced murine dermatitis that resembles human psoriasis, nociceptive sensory neurons were reported to promote the production of proinflammatory cytokine IL-23 by dermal dendritic cells, and this study visualized contacts of dendritic cells with sensory nerve fibers by intravital microscopy [58]. A different study also showed that in anti-fungal immune response skin nociceptors stimulate a dermal dendritic cell subset with a neuropeptide CGRP to promote the IL-23 production, although this study did not perform imaging analysis [34]. In the small intestine, the close association of muscularis macrophages with active myenteric plexus nerves was visualized by using a calcium biosensor. The study concluded that upon bacterial infection, enteric sympathetic nerves release norepinephrine in the myenteric plexus to induce tissue-protective functions of muscularis macrophages that express $\beta 2$ adrenergic receptors [14]. On the other hand, immune cells can produce detrimental effects on neuronal cells in autoimmune diseases. Intravital imaging of the brainstem using a cell death indicator and a calcium biosensor showed the degeneration process of neurons contacted by proinflammatory helper $\mathrm{T}$ cells in the mouse models of multiple sclerosis [64]. The degeneration and regeneration processes were also analyzed by imaging of the explanted spinal cord from mice in which a multiple sclerosis-like disease was induced by the viral infection and neural precursor cells were transplanted [21].

\section{Future perspectives}

As described above, in vivo immune cell dynamics has been analyzed by using the evolving techniques of multicolor visualization, light-induced cell labeling, and monitoring of cellular activities. In order to further improve the physiological understanding of the immune system, future imaging studies need to analyze interactions of the immune system with the other systems in the body by exploiting all of these cuttingedge techniques. For example, simultaneous multicolor visualization of three-way interactions between immune cells, epithelial cells, and nerves in the barrier tissue will likely provide a novel insight into the regulation of inflammation. Intravital imaging analysis of various other cell types such as glial cells [30], whose importance in control of immune cell function is newly discovered, will be also important. In addition, the diversity of epithelial cells, peripheral neurons, glial cells, endothelial cells, and fibroblastic cells need to be clarified in future imaging studies. As for the immune cell diversity, newly discovered important cell types such as various innate lymphoid cells need to be imaged together with other immune cells and non-immune cells [30, 55, 59]. Moreover, activities of immune cells and other cells such as neurons need to be simultaneously monitored to understand functional significance of their interactions. To analyze outcomes in immune cells of their interactions with neurons, optogenetic stimulation of specific neuronal subsets will be also useful [81]. Even if immune cells show outcomes to be analyzed only after more than a day post-interaction, light-induced labeling during the interaction may enable analysis of such outcomes. These approaches will be valuable for exploring the regulation of inflammation not only in the skin and intestine but also in many other tissues of the body.

Acknowledgments We thank Tri Phan for the expert help on twophoton conversion of KikGR cells in the lymph node. This work was supported by the Ministry of Education, Culture, Sports, Science, and Technology of Japan (T.O. and H.I.).

\section{Compliance with ethical standards}

Conflict of interest The authors declare that they have no competing interests.

Open Access This article is distributed under the terms of the Creative Commons Attribution 4.0 International License (http:// creativecommons.org/licenses/by/4.0/), which permits unrestricted use, distribution, and reproduction in any medium, provided you give appropriate credit to the original author(s) and the source, provide a link to the Creative Commons license, and indicate if changes were made.

\section{References}

1. Allen CD, Okada T, Cyster JG (2007) Germinal-center organization and cellular dynamics. Immunity 27:190-202

2. Allen CD, Okada T, Tang HL, Cyster JG (2007) Imaging of germinal center selection events during affinity maturation. Science 315 : $528-531$

3. Ando R, Hama H, Yamamoto-Hino M, Mizuno H, Miyawaki A (2002) An optical marker based on the UV-induced green-to-red photoconversion of a fluorescent protein. Proc Natl Acad Sci U S A 99:12651-12656

4. Aoki K, Kamioka Y, Matsuda M (2013) Fluorescence resonance energy transfer imaging of cell signaling from in vitro to in vivo: basis of biosensor construction, live imaging, and image processing. Dev Growth Differ 55:515-522 
5. Bajenoff M, Egen JG, Koo LY, Laugier JP, Brau F, Glaichenhaus N, Germain RN (2006) Stromal cell networks regulate lymphocyte entry, migration, and territoriality in lymph nodes. Immunity 25 : 989-1001

6. Bedoui S, Heath WR, Mueller SN (2016) CD4(+) T-cell help amplifies innate signals for primary CD8(+) T-cell immunity. Immunol Rev 272:52-64

7. Bousso P, Bhakta NR, Lewis RS, Robey E (2002) Dynamics of thymocyte-stromal cell interactions visualized by two-photon microscopy. Science 296:1876-1880

8. Chtanova T, Hampton HR, Waterhouse LA, Wood K, Tomura M, Miwa Y, Mackay CR, Brink R, Phan TG (2014) Real-time interactive two-photon photoconversion of recirculating lymphocytes for discontinuous cell tracking in live adult mice. J Biophotonics 7: 425-433

9. Daniels NJ, Hyde E, Ghosh S, Seo K, Price KM, Hoshino K, Kaisho T, Okada T, Ronchese F (2016) Antigen-specific cytotoxic $\mathrm{T}$ lymphocytes target airway CD103+ and CD11b + dendritic cells to suppress allergic inflammation. Mucosal Immunol 9:229-239

10. Denk W, Svoboda K (1997) Photon upmanship: why multiphoton imaging is more than a gimmick. Neuron 18:351-357

11. Devi S, Li A, Westhorpe CL, Lo CY, Abeynaike LD, Snelgrove SL, Hall P, Ooi JD, Sobey CG, Kitching AR, Hickey MJ (2013) Multiphoton imaging reveals a new leukocyte recruitment paradigm in the glomerulus. Nat Med 19:107-112

12. Eickhoff S, Brewitz A, Gerner MY, Klauschen F, Komander K, Hemmi H, Garbi N, Kaisho T, Germain RN, Kastenmuller W (2015) Robust anti-viral immunity requires multiple distinct $\mathrm{T}$ cell-dendritic cell interactions. Cell 162:1322-1337

13. Farache J, Koren I, Milo I, Gurevich I, Kim KW, Zigmond E, Furtado GC, Lira SA, Shakhar G (2013) Luminal bacteria recruit $\mathrm{CD} 103+$ dendritic cells into the intestinal epithelium to sample bacterial antigens for presentation. Immunity 38:581-595

14. Gabanyi I, Muller PA, Feighery L, Oliveira TY, Costa-Pinto FA, Mucida D (2016) Neuro-immune interactions drive tissue programming in intestinal macrophages. Cell 164:378-391

15. Garrod KR, Moreau HD, Garcia Z, Lemaitre F, Bouvier I, Albert ML, Bousso P (2012) Dissecting T cell contraction in vivo using a genetically encoded reporter of apoptosis. Cell Rep 2:1438-1447

16. Germain RN, Robey EA, Cahalan MD (2012) A decade of imaging cellular motility and interaction dynamics in the immune system. Science 336:1676-1681

17. Gerner MY, Kastenmuller W, Ifrim I, Kabat J, Germain RN (2012) Histo-cytometry: a method for highly multiplex quantitative tissue imaging analysis applied to dendritic cell subset microanatomy in lymph nodes. Immunity 37:364-376

18. Gerner MY, Torabi-Parizi P, Germain RN (2015) Strategically localized dendritic cells promote rapid $\mathrm{T}$ cell responses to lymphborne particulate antigens. Immunity 42:172-185

19. Ghigo C, Mondor I, Jorquera A, Nowak J, Wienert S, Zahner SP, Clausen BE, Luche H, Malissen B, Klauschen F, Bajenoff M (2013) Multicolor fate mapping of Langerhans cell homeostasis. J Exp Med 210:1657-1664

20. Green JA, Cyster JG (2012) S1PR2 links germinal center confinement and growth regulation. Immunol Rev 247:36-51

21. Greenberg ML, Weinger JG, Matheu MP, Carbajal KS, Parker I, Macklin WB, Lane TE, Cahalan MD (2014) Two-photon imaging of remyelination of spinal cord axons by engrafted neural precursor cells in a viral model of multiple sclerosis. Proc Natl Acad Sci U S A 111:E2349-E2355

22. Grigorova IL, Panteleev M, Cyster JG (2010) Lymph node cortical sinus organization and relationship to lymphocyte egress dynamics and antigen exposure. Proc Natl Acad Sci U S A 107:20447-20452

23. Grigorova IL, Schwab SR, Phan TG, Pham TH, Okada T, Cyster JG (2009) Cortical sinus probing, S1P1-dependent entry and flowbased capture of egressing T cells. Nat Immunol 10:58-65
24. Guan Y, Watson AJ, Marchiando AM, Bradford E, Shen L, Turner JR, Montrose MH (2011) Redistribution of the tight junction protein ZO-1 during physiological shedding of mouse intestinal epithelial cells. Am J Physiol Cell Physiol 300:C1404-C1414

25. Heath WR, Carbone FR (2009) Dendritic cell subsets in primary and secondary $\mathrm{T}$ cell responses at body surfaces. Nat Immunol 10: 1237-1244

26. Heath WR, Carbone FR (2013) The skin-resident and migratory immune system in steady state and memory: innate lymphocytes, dendritic cells and T cells. Nat Immunol 14:978-985

27. Hiratsuka T, Fujita Y, Naoki H, Aoki K, Kamioka Y, Matsuda M (2015) Intercellular propagation of extracellular signal-regulated kinase activation revealed by in vivo imaging of mouse skin. Elife 4:e 05178

28. Hong M, Jung E, Yang S, Jung W, Seong YJ, Park E, Bramos A, Kim KE, Lee S, Daghlian G, Seo JI, Choi I, Choi IS, Koh CJ, Kobielak A, Ying QL, Johnson M, Gardner D, Wong AK, Choi D, Hong YK (2016) Efficient assessment of developmental, surgical and pathological lymphangiogenesis using a lymphatic reporter mouse and its embryonic stem cells. PLoS One 11:e0157126

29. Hor JL, Whitney PG, Zaid A, Brooks AG, Heath WR, Mueller SN (2015) Spatiotemporally distinct interactions with dendritic cell subsets facilitates CD4+ and CD8+ $\mathrm{T}$ cell activation to localized viral infection. Immunity 43:554-565

30. Ibiza S, Garcia-Cassani B, Ribeiro H, Carvalho T, Almeida L, Marques R, Misic AM, Bartow-McKenney C, Larson DM, Pavan WJ, Eberl G, Grice EA, Veiga-Fernandes H (2016) Glial-cellderived neuroregulators control type 3 innate lymphoid cells and gut defence. Nature 535:440-443

31. Jain R, Tikoo S, Weninger W (2016) Recent advances in microscopic techniques for visualizing leukocytes in vivo. F1000Res 5

32. Jarjour M, Jorquera A, Mondor I, Wienert S, Narang P, Coles MC, Klauschen F, Bajenoff M (2014) Fate mapping reveals origin and dynamics of lymph node follicular dendritic cells. J Exp Med 211: $1109-1122$

33. Kamioka Y, Sumiyama K, Mizuno R, Sakai Y, Hirata E, Kiyokawa E, Matsuda M (2012) Live imaging of protein kinase activities in transgenic mice expressing FRET biosensors. Cell Struct Funct 37: $65-73$

34. Kashem SW, Riedl MS, Yao C, Honda CN, Vulchanova L, Kaplan DH (2015) Nociceptive sensory fibers drive interleukin-23 production from $\mathrm{CD} 301 \mathrm{~b}+$ dermal dendritic cells and drive protective cutaneous immunity. Immunity 43:515-526

35. Kitano M, Moriyama S, Ando Y, Hikida M, Mori Y, Kurosaki T, Okada T (2011) Bcl6 protein expression shapes pre-germinal center $\mathrm{B}$ cell dynamics and follicular helper T cell heterogeneity. Immunity 34:961-972

36. Kitano M, Yamazaki C, Takumi A, Ikeno T, Hemmi H, Takahashi N, Shimizu K, Fraser SE, Hoshino K, Kaisho T, Okada T (2016) Imaging of the cross-presenting dendritic cell subsets in the skindraining lymph node. Proc Natl Acad Sci U S A 113:1044-1049

37. Kiyokawa E, Aoki K, Nakamura T, Matsuda M (2011) Spatiotemporal regulation of small GTPases as revealed by probes based on the principle of Forster Resonance Energy Transfer (FRET): implications for signaling and pharmacology. Annu Rev Pharmacol Toxicol 51:337358

38. Kubo A, Nagao K, Yokouchi M, Sasaki H, Amagai M (2009) External antigen uptake by Langerhans cells with reorganization of epidermal tight junction barriers. J Exp Med 206:2937-2946

39. Le Borgne M, Raju S, Zinselmeyer BH, Le VT, Li J, Wang Y, Miller MJ, Shaw AS (2016) Real-time analysis of calcium signals during the early phase of $\mathrm{T}$ cell activation using a genetically encoded calcium biosensor. J Immunol 196:1471-1479

40. Liu D, Xu H, Shih C, Wan Z, Ma X, Ma W, Luo D, Qi H (2015) TB-cell entanglement and ICOSL-driven feed-forward regulation of germinal centre reaction. Nature 517:214-218 
41. Lodygin D, Odoardi F, Schlager C, Korner H, Kitz A, Nosov M, van den Brandt J, Reichardt HM, Haberl M, Flugel A (2013) A combination of fluorescent NFAT and H2B sensors uncovers dynamics of $\mathrm{T}$ cell activation in real time during CNS autoimmunity. Nat Med 19:784-790

42. Maeda H, Kowada T, Kikuta J, Furuya M, Shirazaki M, Mizukami S, Ishii M, Kikuchi K (2016) Real-time intravital imaging of $\mathrm{pH}$ variation associated with osteoclast activity. Nat Chem Biol 12: $579-585$

43. Marangoni F, Murooka TT, Manzo T, Kim EY, Carrizosa E, Elpek NM, Mempel TR (2013) The transcription factor NFAT exhibits signal memory during serial $\mathrm{T}$ cell interactions with antigenpresenting cells. Immunity 38:237-249

44. McDole JR, Wheeler LW, McDonald KG, Wang B, Konjufca V, Knoop KA, Newberry RD, Miller MJ (2012) Goblet cells deliver luminal antigen to CD103+ dendritic cells in the small intestine. Nature 483:345-349

45. Miller MJ, Wei SH, Cahalan MD, Parker I (2003) Autonomous T cell trafficking examined in vivo with intravital two-photon microscopy. Proc Natl Acad Sci U S A 100:2604-2609

46. Miller MJ, Wei SH, Parker I, Cahalan MD (2002) Two-photon imaging of lymphocyte motility and antigen response in intact lymph node. Science 296:1869-1873

47. Mionnet C, Sanos SL, Mondor I, Jorquera A, Laugier JP, Germain RN, Bajenoff M (2011) High endothelial venules as traffic control points maintaining lymphocyte population homeostasis in lymph nodes. Blood 118:6115-6122

48. Mizuno R, Kamioka Y, Kabashima K, Imajo M, Sumiyama K, Nakasho E, Ito T, Hamazaki Y, Okuchi Y, Sakai Y, Kiyokawa E, Matsuda M (2014) In vivo imaging reveals PKA regulation of ERK activity during neutrophil recruitment to inflamed intestines. J Exp Med 211:1123-1136

49. Mizuno R, Kamioka Y, Sakai Y, Matsuda M (2016) Visualization of signaling molecules during neutrophil recruitment in transgenic mice expressing FRET biosensors. Methods Mol Biol 1422:149160

50. Moriyama S, Takahashi N, Green JA, Hori S, Kubo M, Cyster JG, Okada T (2014) Sphingosine-1-phosphate receptor 2 is critical for follicular helper T cell retention in germinal centers. J Exp Med 211: 1297-1305

51. Mues M, Bartholomaus I, Thestrup T, Griesbeck O, Wekerle H, Kawakami N, Krishnamoorthy G (2013) Real-time in vivo analysis of $\mathrm{T}$ cell activation in the central nervous system using a genetically encoded calcium indicator. Nat Med 19:778-783

52. Natsuaki Y, Egawa G, Nakamizo S, Ono S, Hanakawa S, Okada T, Kusuba N, Otsuka A, Kitoh A, Honda T, Nakajima S, Tsuchiya S, Sugimoto Y, Ishii KJ, Tsutsui H, Yagita H, Iwakura Y, Kubo M, Ng L, Hashimoto T, Fuentes J, Guttman-Yassky E, Miyachi Y, Kabashima K (2014) Perivascular leukocyte clusters are essential for efficient activation of effector T cells in the skin. Nat Immunol 15:1064-1069

53. Ordovas-Montanes J, Rakoff-Nahoum S, Huang S, Riol-Blanco L, Barreiro O, von Andrian UH (2015) The regulation of immunological processes by peripheral neurons in homeostasis and disease. Trends Immunol 36:578-604

54. Patterson GH, Lippincott-Schwartz J (2002) A photoactivatable GFP for selective photolabeling of proteins and cells. Science 297:1873-1877

55. Pearson C, Thornton EE, McKenzie B, Schaupp AL, Huskens N, Griseri T, West N, Tung S, Seddon BP, Uhlig HH, Powrie F (2016) ILC3 GM-CSF production and mobilisation orchestrate acute intestinal inflammation. Elife 5:e10066

56. Pesic M, Bartholomaus I, Kyratsous NI, Heissmeyer V, Wekerle H, Kawakami N (2013) 2-photon imaging of phagocyte-mediated T cell activation in the CNS. J Clin Invest 123:1192-1201
57. Qi H, Egen JG, Huang AY, Germain RN (2006) Extrafollicular activation of lymph node B cells by antigen-bearing dendritic cells. Science 312:1672-1676

58. Riol-Blanco L, Ordovas-Montanes J, Perro M, Naval E, Thiriot A, Alvarez D, Paust S, Wood JN, von Andrian UH (2014) Nociceptive sensory neurons drive interleukin-23-mediated psoriasiform skin inflammation. Nature 510:157-161

59. Roediger B, Kyle R, Yip KH, Sumaria N, Guy TV, Kim BS, Mitchell AJ, Tay SS, Jain R, Forbes-Blom E, Chen X, Tong PL, Bolton HA, Artis D, Paul WE, Fazekas de St Groth B, Grimbaldeston MA, Le Gros G, Weninger W (2013) Cutaneous immunosurveillance and regulation of inflammation by group 2 innate lymphoid cells. Nat Immunol 14:564-573

60. Schiessl IM, Castrop H (2016) Deep insights: intravital imaging with two-photon microscopy. Pflugers Arch

61. Schneider M, Barozzi S, Testa I, Faretta M, Diaspro A (2005) Twophoton activation and excitation properties of PA-GFP in the 720920-nm region. Biophys J 89:1346-1352

62. Shulman Z, Gitlin AD, Targ S, Jankovic M, Pasqual G, Nussenzweig MC, Victora GD (2013) T follicular helper cell dynamics in germinal centers. Science 341:673-677

63. Shulman Z, Gitlin AD, Weinstein JS, Lainez B, Esplugues E, Flavell RA, Craft JE, Nussenzweig MC (2014) Dynamic signaling by $\mathrm{T}$ follicular helper cells during germinal center $\mathrm{B}$ cell selection. Science 345:1058-1062

64. Siffrin V, Radbruch H, Glumm R, Niesner R, Paterka M, Herz J, Leuenberger T, Lehmann SM, Luenstedt S, Rinnenthal JL, Laube G, Luche H, Lehnardt S, Fehling HJ, Griesbeck O, Zipp F (2010) In vivo imaging of partially reversible th 17 cell-induced neuronal dysfunction in the course of encephalomyelitis. Immunity 33:424 436

65. Snippert HJ, van der Flier LG, Sato T, van Es JH, van den Born M, Kroon-Veenboer C, Barker N, Klein AM, van Rheenen J, Simons $\mathrm{BD}$, Clevers H (2010) Intestinal crypt homeostasis results from neutral competition between symmetrically dividing Lgr5 stem cells. Cell 143:134-144

66. Stark K, Eckart A, Haidari S, Tirniceriu A, Lorenz M, von Bruhl ML, Gartner F, Khandoga AG, Legate KR, Pless R, Hepper I, Lauber K, Walzog B, Massberg S (2013) Capillary and arteriolar pericytes attract innate leukocytes exiting through venules and 'instruct' them with pattern-recognition and motility programs. Nat Immunol 14:41-51

67. Stoll S, Delon J, Brotz TM, Germain RN (2002) Dynamic imaging of T cell-dendritic cell interactions in lymph nodes. Science 296: 1873-1876

68. Suan D, Nguyen A, Moran I, Bourne K, Hermes JR, Arshi M, Hampton HR, Tomura M, Miwa Y, Kelleher AD, Kaplan W, Deenick EK, Tangye SG, Brink R, Chtanova T, Phan TG (2015) $\mathrm{T}$ follicular helper cells have distinct modes of migration and molecular signatures in naive and memory immune responses. Immunity 42:704-718

69. Sujino T, London M, Hoytema van Konijnenburg DP, Rendon T, Buch T, Silva HM, Lafaille JJ, Reis BS, Mucida D (2016) Tissue adaptation of regulatory and intraepithelial CD4(+) T cells controls gut inflammation. Science 352:1581-1586

70. Tas JM, Mesin L, Pasqual G, Targ S, Jacobsen JT, Mano YM, Chen CS, Weill JC, Reynaud CA, Browne EP, Meyer-Hermann M, Victora GD (2016) Visualizing antibody affinity maturation in germinal centers. Science 351:1048-1054

71. Thestrup T, Litzlbauer J, Bartholomaus I, Mues M, Russo L, Dana H, Kovalchuk Y, Liang Y, Kalamakis G, Laukat Y, Becker S, Witte G, Geiger A, Allen T, Rome LC, Chen TW, Kim DS, Garaschuk O, Griesinger C, Griesbeck O (2014) Optimized ratiometric calcium sensors for functional in vivo imaging of neurons and $\mathrm{T}$ lymphocytes. Nat Methods 11:175-182 
72. Tomura M, Hata A, Matsuoka S, Shand FH, Nakanishi Y, Ikebuchi R, Ueha S, Tsutsui H, Inaba K, Matsushima K, Miyawaki A, Kabashima K, Watanabe T, Kanagawa O (2014) Tracking and quantification of dendritic cell migration and antigen trafficking between the skin and lymph nodes. Sci Rep 4:6030

73. Tomura M, Honda T, Tanizaki H, Otsuka A, Egawa G, Tokura Y, Waldmann H, Hori S, Cyster JG, Watanabe T, Miyachi Y, Kanagawa O, Kabashima K (2010) Activated regulatory T cells are the major $\mathrm{T}$ cell type emigrating from the skin during a cutaneous immune response in mice. J Clin Invest 120:883-893

74. Tsutsui H, Karasawa S, Shimizu H, Nukina N, Miyawaki A (2005) Semi-rational engineering of a coral fluorescent protein into an efficient highlighter. EMBO Rep 6:233-238

75. Veiga-Fernandes H, Mucida D (2016) Neuro-immune interactions at barrier surfaces. Cell 165:801-811

76. Victora GD, Nussenzweig MC (2012) Germinal centers. Annu Rev Immunol 30:429-457

77. Victora GD, Schwickert TA, Fooksman DR, Kamphorst AO, Meyer-Hermann M, Dustin ML, Nussenzweig MC (2010) Germinal center dynamics revealed by multiphoton microscopy with a photoactivatable fluorescent reporter. Cell 143:592-605
78. Wei SH, Rosen H, Matheu MP, Sanna MG, Wang SK, Jo E, Wong CH, Parker I, Cahalan MD (2005) Sphingosine 1-phosphate type 1 receptor agonism inhibits transendothelial migration of medullary $\mathrm{T}$ cells to lymphatic sinuses. Nat Immunol 6:1228-1235

79. Wei SH, Safrina O, Yu Y, Garrod KR, Cahalan MD, Parker I (2007) $\mathrm{Ca} 2+$ signals in CD4+ $\mathrm{T}$ cells during early contacts with antigen-bearing dendritic cells in lymph node. J Immunol 179:1586-1594

80. Whitaker M (2010) Genetically encoded probes for measurement of intracellular calcium. Methods Cell Biol 99:153-182

81. Williams EK, Chang RB, Strochlic DE, Umans BD, Lowell BB, Liberles SD (2016) Sensory neurons that detect stretch and nutrients in the digestive system. Cell 166:209-221

82. Yasuda R (2012) Imaging intracellular signaling using two-photon fluorescent lifetime imaging microscopy. Cold Spring Harb Protoc 2012:1121-1128

83. Yoshikawa S, Usami T, Kikuta J, Ishii M, Sasano T, Sugiyama K, Furukawa T, Nakasho E, Takayanagi H, Tedder TF, Karasuyama H, Miyawaki A, Adachi T (2016) Intravital imaging of $\mathrm{Ca}(2+)$ signals in lymphocytes of $\mathrm{Ca}(2+)$ biosensor transgenic mice: indication of autoimmune diseases before the pathological onset. Sci Rep 6:18738 